University of Wollongong

Research Online

Faculty of Engineering and Information

Faculty of Engineering and Information

Sciences - Papers: Part B

Sciences

2017

\title{
Analysis of a compact annular-radial-orifice flow magnetorheological valve and evaluation of its performance
}

\author{
Guoliang $\mathrm{Hu}$ \\ University of Wollongong, ghu@uow.edu.au \\ Mingke Liao \\ East China Jiaotong University \\ Weihua Li \\ University of Wollongong, weihuali@uow.edu.au
}

Follow this and additional works at: https://ro.uow.edu.au/eispapers1

Part of the Engineering Commons, and the Science and Technology Studies Commons

Research Online is the open access institutional repository for the University of Wollongong. For further information contact the UOW Library: research-pubs@uow.edu.au 


\title{
Analysis of a compact annular-radial-orifice flow magnetorheological valve and evaluation of its performance
}

\author{
Abstract \\ This article outlines a compact annular-radial-orifice flow magnetorheological valve through theoretical \\ calculation, simulation analysis and experiment verification. The fluid flow paths of this proposed \\ magnetorheological valve consist of a single annular flow channel, a single radial flow channel and an \\ orifice flow channel through structural design. The finite element modelling and analysis of the \\ magnetorheological valve was carried out using ANSYS/Emag software, including achieving optimal \\ magnetic field distribution and yield stress in the annular flow path and radial flow path, respectively. \\ Moreover, this proposed magnetorheological valve was prototyped and evaluated experimentally, showing \\ that the magnetorheological valve has significantly improved its efficiency, especially the pressure drop at \\ the $1.0 \mathrm{~mm}$ width of annular resistance gap and $0.5 \mathrm{~mm}$ width of radial resistance gap.

\section{Disciplines} \\ Engineering | Science and Technology Studies

\section{Publication Details} \\ Hu, G., Liao, M. \& Li, W. (2017). Analysis of a compact annular-radial-orifice flow magnetorheological valve \\ and evaluation of its performance. Journal of Intelligent Material Systems and Structures, 28 (10), \\ 1322-1333.
}




\title{
Analysis of a compact annular-radial-orifice flow magnetorheological valve and evaluation of its performance
}

\author{
Guoliang $\mathrm{Hu}^{1,2,{ }^{*}}$, Mingke Liao ${ }^{1}$, and Weihua $\mathrm{Li}^{2, *}$ \\ ${ }^{1}$ School of Mechatronic Engineering, East China Jiaotong University, Nanchang, Jiangxi Province \\ 330013, China \\ ${ }^{2}$ School of Mechanical, Materials and Mechatronic Engineering, University of Wollongong, \\ Wollongong, NSW 2522, Australia \\ *Author to whom any correspondence should be addressed. \\ E-mails: glhu@ecjtu.edu.cn,weihuali@uow.edu.au
}

\begin{abstract}
This paper outlines a compact annular-radial-orifice flow magnetorheological (MR) valve through theoretical calculation, simulation analysis and experiment verification. The fluid flow paths of this proposed MR valve consist of a single annular flow channel, a single radial flow channel and an orifice flow channel through structural design. The finite element modelling and analysis of the MR valve was carried out using ANSYS/Emag software, including achieving optimal magnetic field distribution and yield stress in the annular flow path and radial flow path, respectively. Moreover, this proposed MR valve was prototyped and evaluated experimentally, showing that the MR valve has significantly improved its efficiency, especially the pressure drop at the $1.0 \mathrm{~mm}$ width of annular resistance gap and $0.5 \mathrm{~mm}$ width of radial resistance gap.
\end{abstract}

\section{Keywords}

MR valve, annular-radial-orifice flow, structural design, pressure drop, finite element analysis

\section{Introduction}

Magnetorheological (MR) fluid is a suspension of micro sized particles dispersed in non-magnetic carrying fluids. As a kind of smart materials, MR fluid exhibits unusual characteristics in that its rheological properties can be continuously and reversibly changed within milliseconds by applying or removing a magnetic field (Jolly et al., 1999; De Vicente et al., 2011). This interesting property has inspired the design of a large variety of MR fluid based devices in various engineering applications, such as MR damper, MR mount, MR brake and MR clutch (Li et al., 2003; Li and Du, 2003; Liu et al., 2006; Phu et al., 2014a; Do et al., 2015 ). Since the working principles of most MR fluid based devices are based on the manipulation of fluid flow rate in the resistance gaps, the key performance of MR fluid based device is determined by the performance of MR valve. Therefore, a successful improvement of MR valve performance can significantly impact the development of other MR fluid based devices.

In general, a typical MR valve consists of a valve body, a valve core, an excitation coil and a fluid flow path. The detailed configuration of each MR valve could be different depending on the specific design but the basic working principle is usually similar. The magnetic field from the excitation coil is applied to the MR fluid in the fluid flow path to make its rheological properties to change, which 
leads to the changes of the fluid flow resistance and therefore changes the pressure drop of the valve, so that the MR fluid flow can be slowed or even stopped (Abd Fatah et al., 2015; Kostamo et al., 2012; Yoshida et al., 2010). Normally, the MR valve is often used to control the speed of the hydraulic actuator or acts as a bypass valve to control the damping performance of the MR actuators (Hu et al., 2014a; McLaughlin et al., 2014; Nguyen et al., 2013; Phu et al., 2014b).

In order to make the MR valve to control the MR actuators conveniently and effectively, the research of MR valves was mainly focused on the structural design and optimisation to achieve a larger pressure drop or fast responses while miniature its geometry as possible as it can. Such as, Salloom (2011a, 2011b, 2012) proposed a four way and three position MR proportional directional control valve, and the experimental results show that it can replace many types of spool directional control valve for controlling hydraulic actuator. Aydar et al. (2010) and Gordaninejad et al. (2010) developed a large-scale modular MRF bypass damper with a two-stage disk type bypass MR valve which can provide a pressure drop of over 9.6 MPa at 5A of activation electric input current, the experimental results showed that the proposed modular MRF bypass damper can provide a maximum damping force over $200 \mathrm{KN}$. Liao et al. (2012) developed a novel MR valve with multi-stage radial fluid flow paths, and a MR damper was also prototyped integrated with this bypass MR valve, the simulation and experimental results showed that this new MR damper is superior to the traditional MR damper with annular damping channel in the performances of low magnetic field utilization and high energy consumption. We presented an efficient double coil MR valve with evaluated simulations and experimental verifications (Hu et al., 2014a); and a novel MR valve with tunable resistance gaps from minimum $1 \mathrm{~mm}$ to maximum $2 \mathrm{~mm}$ was also proposed, the experimental tests showed that this MR valve can offer a great flexibility in developing pressure drops (Hu et al., 2014b).

In addition to the structural design of MR valves, the optimisation of MR valves was also carried out to improve the performance of MR valves. Rosenfield and Wereley (2004) proposed an analytical optimisation design method for MR valves and dampers based on the assumption of a constant magnetic flux density throughout the magnetic circuit to ensure that one region of the magnetic circuit does not become prematurely saturated and cause a bottleneck. Yoo et al. (2002, 2004) developed a design that maximised performance while minimising the volume and mass consumption of the valve from the fluid mechanics purpose. Nguyen et al. (2007, 2008, 2009) presented a geometric optimal design of MR valves constrained in a specific volume using the finite element method to improve pressure drop of the valve. Zhu et al. (2013) investigated the optimal design of MR control valves with an annular flow structure in two configurations of coil wire placements using a non-dimensional analytical method. Hadadian et al. (2014) also used the design of experiments and response surface method for the optimal design of a single coil annular MR valve constrained in a specific volume inside a MR damper.

It is noted that the fluid flow paths of the MR valves were only either annular resistance gap or radial resistance gap. For this typical fluid flow channel, it is difficult to obtain a larger pressure drop and bigger dynamic range constrained in a specific volume dimensions, which hinder the potential applications of MR valve to some extent. To this end, an MR valve with hybrid annular-radial fluid flow paths was proposed. Currently, only two research groups investigate the performance of the MR valves with the hybrid annular-radial fluid flow resistance gaps. One group 
is from Chongqing University in China, and the other group is from Universiti Teknologi Malaysis. Ai et al. (2006), from the first group, proposed a MR valve with the hybrid annular-radial fluid flow resistance gaps simultaneously to increase the pressure drop, where the fluid flow paths consists of two radial flow channels, two annular flow channels and one orifice channel. However, the pressure drop of this valve is not optimized because its design was based on the assumption that the magnetic flux densities in the annular and radial fluid flow gaps were identical. For the second group, Imaduddin et al. (2014, 2015) extended to develop a compact MR valve with multiple annular and radial gaps. Both simulation and experimental results revealed that this new design could increase the achievable pressure drop of the valve by more than $2.5 \mathrm{MPa}$. However, the whole flow path is formed by five annular, six radial and two orifice channels, which is extremely complex in structure and prune to blocking though it gained a favorable pressure drop. Furthermore, the pressure drop is mainly attributed to the six radial flow channels rather than other channels, which is actually a radial type MR valve.

To address the above shortcomings, we developed a novel MR valve with the hybrid annular-radial-orifice flow path. On one hand, this MR valve is different from those MR valves listed in the literatures because its fluid flow paths were composed of a single annular flow channel, a single radial flow channel and an orifice flow channel through compact structural design. It is actually an asymmetrical valve. On the other hand, the pressure drop of the valve was investigated through theoretical calculation, simulation analysis and experiment verification by taking into account the optimal distribution of the length of annular flow channel and radial flow channel to obtain the maximum dynamic yield stress before saturation. In other words, this design can make full use of the high utilization of the magnetic flux density both in the radial resistance gap and in the annular resistance gap. This design methodology not only guarantees a larger pressure drop but also miniaturises the geometry of the proposed MR valve, also reduces the risk of blocking during the working state.

\section{Design and development of the MR valve with annular-radial-orifice flow paths}

\subsection{Structural design of the MR valve}

The structure of the MR valve with annular-radial-orifice flow paths is shown in Figure 1. In the design, the left head cover and right head cover are made from stainless steel materials, and there are six threaded holes as a holder for the screw and one fluid flow channel port acts as inlet/outlet port of the MR valve. The flow guided plate, which is made from stainless steel material, acts as a connecting passage between the inlet port and the annular flow channel. It can make that the fluid has a state of laminated flow to avoid turbulence. At the same time, it can also reduce the impact of the MR fluid on the magnetic plate. The excitation coil was wound onto the groove formed by the fixed plate and the valve core, and protruded out through a hole in the right head cover. The assembly between the fixed plate and the valve core was dependent on the screw joints at the left end of the valve core. The screw was used to fix the magnetic plate, the washer and the fixed plate together. The radial resistance gap was guaranteed by the thickness of the washer.

The annular-radial-orifice flow paths in the proposed MR valve were comprised of a single annular flow path, a radial flow path and an orifice flow path. In detail, the annular flow path was formed between the outer circumference of the magnetic plate and the inner circumference of the valve 
body; while the radial fluid flow path was looped between the right surface of the magnetic plate and the left surface of the valve core. There was a through hole with diameter of $4 \mathrm{~mm}$ in the middle of the valve core, and it formed the orifice flow path of the MR valve. In addition, the proposed MR valve has a compact structure with an outer diameter size of $62 \mathrm{~mm}$ and overall length of $80 \mathrm{~mm}$ because it only has a single annular path and a single radial flow path. It is actually an asymmetrical valve. This structural design is different from those valves reported by other two groups [Ai et al. (2006), Imaduddin et al. (2014, 2015)].

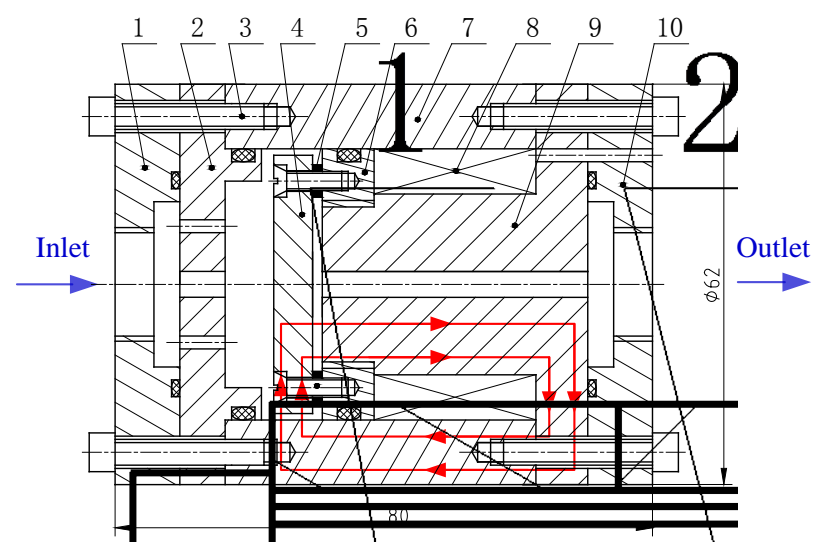

(a)

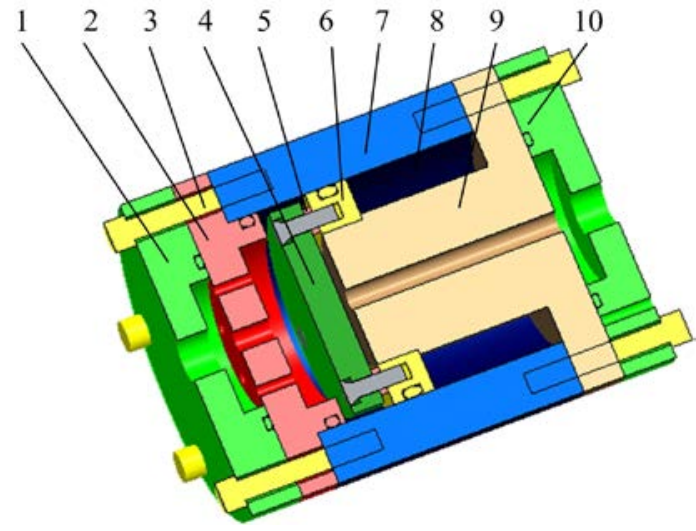

(b)

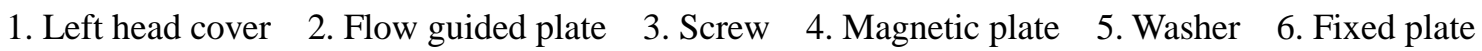
7. Valve body $\quad 8$. Excitation coil 9.Valve core 10 . Right head cover

Figure 1. Configuration of the MR valve: (a) 2D configuration and (b) 3D CAD model

When a constant direct current is applied to the excitation coil, the closed loop magnetic circuits will be generated in the valve body, the annular flow resistance gap, the magnetic plate, the radial resistance gap and the valve core, and the intense magnetic fields will generate in both of the resistance gaps that are perpendicular to the gaps. A pressure drop between the inlet port and the outlet port of the proposed MR valve will be produced because of the shear stress in both of the resistance gaps. Therefore by adjusting the direct current, this pressure drop can be controlled.

\subsection{Magnetic circuit of the MR valve}

Figure 2 shows the simplified magnetic circuit of the proposed MR valve. According to the principle of the continuity of magnetic flux to determine the magnetic flux density throughout its conduit, it is considered as

$$
\Phi_{\mathrm{MR}, \mathrm{r}}=\Phi_{\mathrm{MR}, \mathrm{a}}=\Phi_{\text {steel }}=\Phi
$$

where $\Phi$ is the magnetic flux of the circuit, $\Phi_{\mathrm{MR}, \mathrm{a}}$ and $\Phi_{\mathrm{MR}, \mathrm{r}}$ are the magnetic flux of the MR fluid in the annular fluid flow path and radial fluid flow path, respectively; and $\Phi_{\text {steel }}$ is the magnetic flux of the valve body, valve core and magnetic plate in the primary magnetic path.

The magnetic circuit is analysed using the magnetic Kirchhoff's law as follows:

$$
N_{c} I=\oint_{c} H d l=\sum_{i=1}^{n} H_{i} l_{i}
$$

where $N_{\mathrm{c}}$ is the number of turns of the excitation coil and $I$ is the current applied to the excitation 
coil, $H_{\mathrm{i}}$ is the magnetic field intensity in the ith link of the circuit, and $l_{\mathrm{i}}$ is the overall effective length of that link.

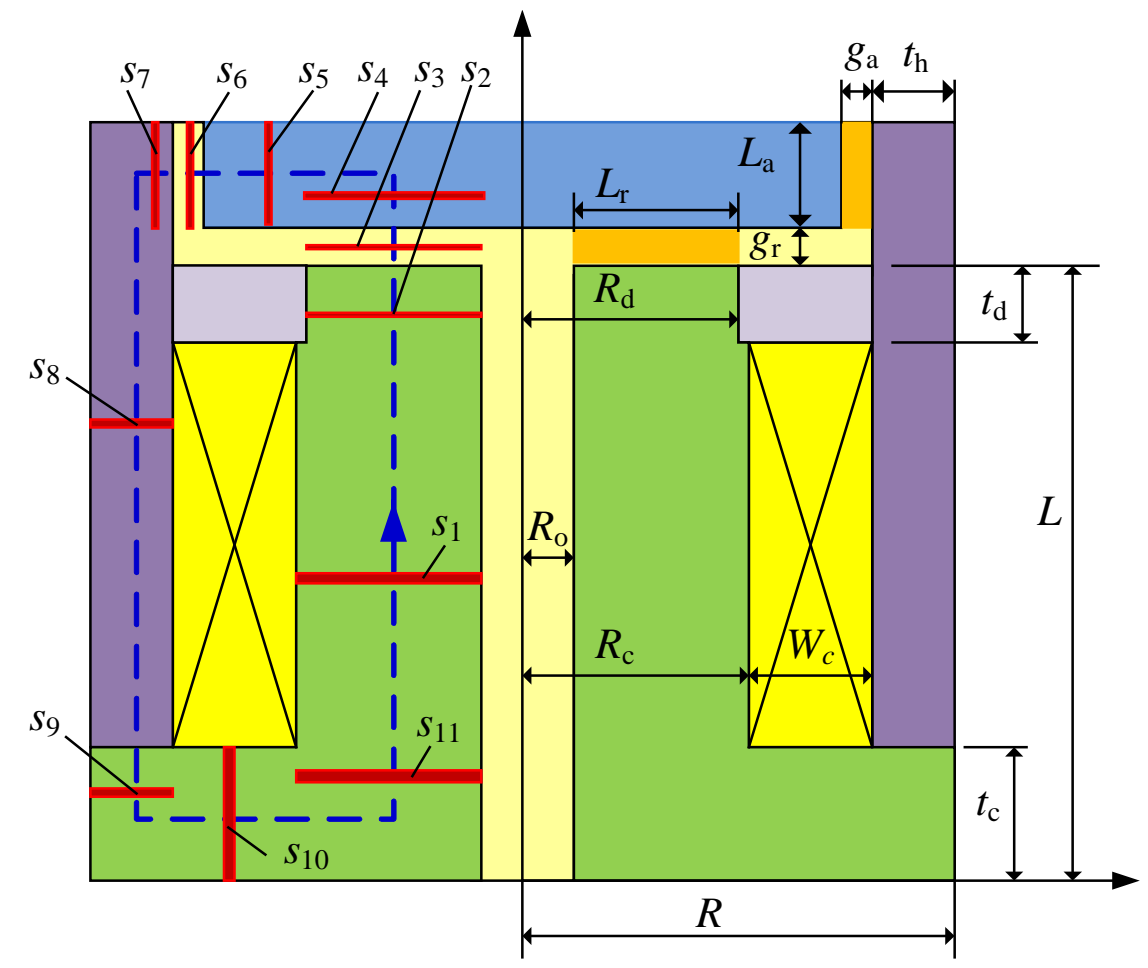

Figure 2. The simplified magnetic circuit of the proposed MR valve

On the other hand, the magnetic flux conservation rule of the circuit is given by

$$
\Phi=\oint_{c} B d S=B_{i} S_{i}
$$

where $B_{\mathrm{i}}$ and $S_{\mathrm{i}}$ are the magnetic flux density and cross sectional area of the ith link, respectively.

For the proposed MR valve that shown in Figure 1 and Figure 2, the effective length of the ith link of the circuit can be defined as

$$
\begin{aligned}
& l_{1}=L-t_{d}-t_{c}, \quad l_{2}=t_{d}, \quad l_{3}=g_{r}, \\
& l_{4}=0.5 L_{a}, \quad l_{5}=R-g_{a}-t_{h}-0.5 R_{d}-0.5 R_{0}, \\
& l_{6}=g_{a}, \quad l_{7}=0.5 t_{h}, \quad l_{8}=L+0.5 L_{a}+g_{r}-t_{c}, \\
& l_{9}=0.5 t_{c}, \quad l_{10}=R-0.5 t_{h}-0.5 R_{c}-0.5 R_{0}, \quad l_{11}=0.5 t_{c}
\end{aligned}
$$

The cross sectional area of the ith link in the magnetic flux path can be calculated by:

$$
\begin{aligned}
& S_{1}=S_{11}=\pi\left[R_{c}^{2}-R_{0}^{2}\right] \\
& S_{2}=S_{4}=\pi\left[R_{d}^{2}-R_{0}^{2}\right] \\
& S_{3}=S_{M R, r}=\pi\left[R_{d}^{2}-R_{0}^{2}\right] \\
& S_{5}=\pi\left(R-g_{a}-t_{h}+0.5 R_{d}+0.5 R_{0}\right) L_{a} \\
& S_{6}=S_{M R, a}=2 \pi\left(R-t_{h}-0.5 g_{a}\right) L_{a} \\
& S_{7}=2 \pi\left(R-0.75 t_{h}\right) L_{a} \\
& S_{8}=S_{9}=\pi\left[R^{2}-\left(R_{c}+W_{c}\right)^{2}\right] \\
& S_{10}=\pi\left(R-0.5 t_{h}+0.5 R_{c}+0.5 R_{0}\right) t_{c}
\end{aligned}
$$


According to electromagnetic theory, the magnetic flux density B can be approximately expressed in terms of the magnetic field intensity $\mathrm{H}$ as follows:

$$
B_{i}=\mu_{0} \mu_{i} H_{i}
$$

where $\mu_{0}=4 \pi \times 10^{-7} \mathrm{TmA}^{-1}$ is the magnetic permeability of free space and $\mu_{\mathrm{i}}$ is the relative magnetic permeability of magnetic materials.

Let $R_{\mathrm{i}}$ represent the magnetic resistance of the $i$ th link in the magnetic flux path, the equation of $R_{\mathrm{i}}$ cab be expressed as

$$
R_{i}=\frac{l_{i}}{\mu_{0} \mu_{i} S_{i}}
$$

So, the equation of magnetic Kirchhoff's law can be rewritten as

$$
N_{c} I=\sum_{i=1}^{n} H_{i} l_{i}=\sum_{i=1}^{n} \frac{B_{i}}{\mu_{0} \mu_{i}} l_{i}=\sum_{i=1}^{n} \frac{l_{i}}{\mu_{0} \mu_{i} S_{i}} \Phi=\sum_{i=1}^{n} R_{i} \Phi
$$

The magnetic flux density of each part of the MR valve can be expressed in the following form and respectively upper bounded by the magnetization property of the used magnetic materials.

$$
B_{j}=\frac{\Phi}{S_{j}}=\frac{N_{c} I}{S_{j} \sum_{i=1}^{n} R_{i}} \leq B_{j s a t}
$$

where $B_{\mathrm{jsat}}$ is the saturated magnetic flux density of the corresponding material in the $j$ th link.

According to Eq. (7) and (9), the magnetic flux density of MR fluid in the annular fluid flow path and radial fluid flow path can be obtained, respectively. They are as follows:

$$
\begin{gathered}
B_{M R, a}=\frac{N_{c} I}{S_{6} \sum_{i=1}^{11} R_{i}}=\frac{\mu_{0} N_{c} I}{S_{6} \sum_{i=1}^{11} \frac{l_{i}}{\mu_{i} S_{i}}} \\
B_{M R, r}=\frac{N_{c} I}{S_{3} \sum_{i=1}^{11} R_{i}}=\frac{\mu_{0} N_{c} I}{S_{3} \sum_{i=1}^{11} \frac{l_{i}}{\mu_{i} S_{i}}}
\end{gathered}
$$

\subsection{Control model of the MR valve}

In general, the performance of a MR valve can be determined by its capability to create and regulate pressure drop between the inlet port and the outlet port, although the other capabilities of MR valve such as time response, linearity and hysteresis are also important.

Ignoring the pressure drop induced in the left and right end cover and the flow guided plate, it can be seen that the flow paths consist of one annular gap, one radial gap and one orifice gap together in the MR valve from Figure 2, so the pressure drop $\triangle p$ of the MR valve can be defined as

$$
\Delta p=\Delta p_{a}+\Delta p_{r}+\Delta p_{o}
$$


Where $\triangle p_{a}, \triangle p_{r}, \triangle p_{o}$ represent the pressure drop through the annular fluid flow path, radial fluid flow path and the orifice flow channel, respectively.

The pressure drop $\triangle p_{a}$ in the annular resistance gap is expressed as

$$
\Delta p_{a}=\Delta p_{a, \eta}+\Delta p_{a, \tau}=\frac{6 \eta q L_{a}}{\pi g_{a}^{3}\left(R-g_{a}-t_{h}\right)}+\frac{c \tau_{y, a}}{g_{a}} L_{a}
$$

where $\triangle p_{a, \eta}$ and $\triangle p_{a, \tau}$ are the pressure drop from the viscous properties of the fluid and the pressure drop from the field dependent yield stress of the fluid in the annular resistance gap, respectively. $\eta$ is viscosity without magnetic field, $q$ is system flow rate, $g_{\mathrm{a}}$ is the thickness of the annular resistance gap, $R$ is the radius of the valve, $t_{\mathrm{h}}$ and $L_{\mathrm{a}}$ are the thickness of the valve body and magnetic plate, respectively. $\tau_{\mathrm{y}, \mathrm{a}}$ is the dynamic yield stress in the annular resistance gap that responds to an applied magnetic field, and $c$ is the coefficient which depended on the flow velocity profile, and has a value ranging from a minimum value of 1 to a maximum value of 3 .

The pressure drop $\triangle p_{r}$ in the radial resistance gap is defined as [Ai et al. (2006)]

$$
\Delta p_{r}=\Delta p_{r, \eta}+\Delta p_{r, \tau}=\frac{6 \eta q}{\pi g_{r}^{3}} \ln \frac{R_{c}+W_{c}}{R_{0}}+\frac{\mathrm{c} \tau_{y, r}}{g_{r}}\left(R_{d}-R_{0}\right)
$$

where $\triangle p_{r, \eta}$ and $\triangle p_{r, \tau}$ are the pressure drop from the viscous properties of the fluid and the pressure drop from the field dependent yield stress of the fluid in the radial resistance gap, respectively. $\tau_{\mathrm{y}, \mathrm{r}}$ is the changes of yield stress in the radial resistance gap that responding to an applied magnetic field, $g_{\mathrm{r}}$ is the thickness of the radial resistance gap, $R_{0}$ is radius of the central hole of the valve core, $W \mathrm{c}$ is the thickness of groove of the valve core, $R_{\mathrm{C}}$ is the radius of the valve core the left end without screw thread, and $R_{\mathrm{d}}$ is the radius of the valve core at the left end with screw thread.

The pressure drop $\triangle p_{o}$ in the orifice resistance gap is defined as ( $\mathrm{Li}$ and $\left.\mathrm{Du}, 2003\right)$

$$
\Delta p_{o}=\frac{8 \eta q L}{\pi R_{0}^{4}}
$$

where $L$ is the length of the valve core.

By substituting Eqs. (13)-(15) into Eq. (12), the pressure drop $\triangle p$ of the proposed MR valve is obtained

$$
\Delta p=\frac{6 \eta q L_{a}}{\pi g_{a}^{3}\left(R-g_{a}-t_{h}\right)}+\frac{6 \eta q}{\pi g_{r}{ }^{3}} \ln \frac{R_{c}+W_{c}}{R_{0}}+\frac{8 \eta q L}{\pi R_{0}^{4}}+\frac{c \tau_{y, a}}{g_{a}} L_{a}+\frac{\mathrm{c} \tau_{y, r}}{g_{r}} L_{r}
$$

As shown in equation (16), the pressure drop $\triangle p$ consists of five terms, where the first three terms are constant viscosity pressures without the magnetic fields, and the latter two terms are dependent on the applied magnetic fields.

\section{Modeling and simulation of the MR valve with annular-radial-orifice flow paths}

\subsection{Magnetic properties of MR fluid used in the MR valve}

The MR fluid with the type MRF-J01T provided by the Chongqing Instrument Material Research 
Institute in China was used in the following simulations and experiments. Its field dependent properties are shown in Figure 3. By observing Figure 3(a), the dynamic yield stress of the MR fluid in the annular and radial resistance gaps can be approximated by (Hu et al., 2014b)

$$
\begin{aligned}
& \tau_{y, a}=a_{3} \times B_{M R, a}^{3}+a_{2} \times B_{M R, a}^{2}+a_{1} \times B_{M R, a}+a_{0} \\
& \tau_{y, r}=a_{3} \times B_{M R, r}^{3}+a_{2} \times B_{M R, r}^{2}+a_{1} \times B_{M R, r}+a_{0}
\end{aligned}
$$

where $\alpha_{0}, \alpha_{1}, \alpha_{2}$ and $\alpha_{3}$ are polynomial coefficients that determined by the least-squares fitting of the dynamic yield stress data as a fuction of magnetic flux density, here $\alpha_{0}=0.0182 \mathrm{kPa}, \alpha_{1}=-48.4644$ $\mathrm{kPa} / \mathrm{T}, \alpha_{2}=865.3901 \mathrm{kPa} / \mathrm{T}^{2}$ and $\alpha_{3}=-984.2742 \mathrm{kPa} / \mathrm{T}^{3}$.

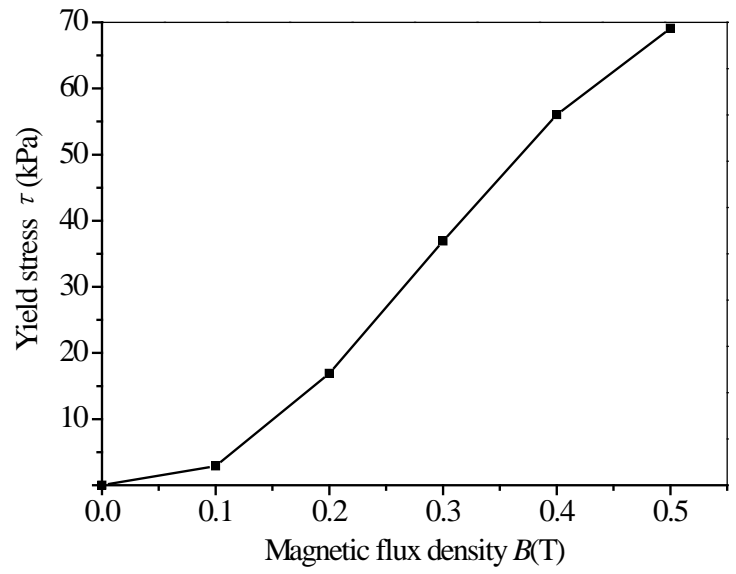

(a)

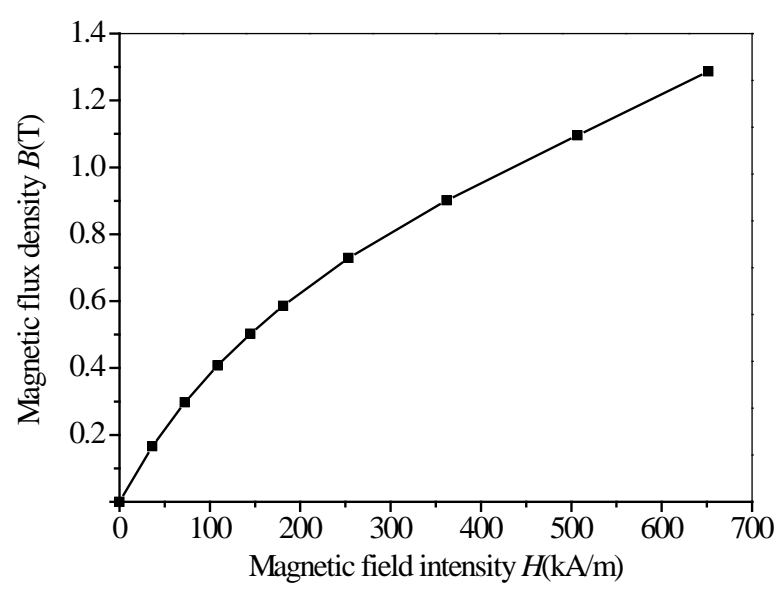

(b)

Figure 3. Specification of the MR fluid with the type MRF-01J: (a) the variation of $\tau$ and $B$, and (b) the variation of $B$ and $H$.

\subsection{Simulation analysis using the FEM method}

Figure 4 show the axisymmetric two dimensional (2D) finite element model of the proposed MR valve using ANSYS/EMAG software. The magnetic plate, the valve core and valve body were made from No. 10 steel, which has a saturated magnetic flux density of $2.4 \mathrm{~T}$ when the applied magnetic field intensity exceeds $320 \mathrm{kA} / \mathrm{m}$. The excitation coil is copper with a relative permeability of 1 . The annular and radial resistance gaps are full of MR fluid whose permeability is defined by the B-H curve of MRF-J01T, as shown in Figure 3(b). When the MR fluid was included in the gap, the solid models of the annular flow channel, radial flow channel and orifice flow channel were established firstly; then they were merged as one entity model; after that, the MR fluid properties were applied to the entity model, finally, the finite element model was established after meshing, which was shown in Figure 4(b). In the simulation, the annular and radial resistance gaps were set $1.0 \mathrm{~mm}$ and $0.5 \mathrm{~mm}$, respectively. The current density in the excitation coil was set at $2.51 \mathrm{~A} / \mathrm{mm}^{2}$ when the applied current to the excitation coil equaled 1.0 A. The diameter of the excitation coil wire was 0.6 $\mathrm{mm}$, and the number of the turns was 400. In the figure 4(b), the entity model was meshed using a quadrangular element with total number of elements 1629 and total number of nodes 5036.

Figure 5 shows the distribution of magnetic flux line and contour of magnetic flux density in the MR valve. Observing figure 5(a), the magnetic flux lines generated by the excitation coil first pass through the valve core, then arrive at the magnetic plate via the radial resistance gap, it 
perpendicularly pass though the annular resistance gap before reach the valve body, and ultimately return back to the valve core to form a closed loop. The magnetic flux lines in the MR valve are mainly distributed along the primary magnetic flux path, which is consistent with the ideal case. However, the magnetic flux leakage is existed, which will affect the performance of the MR valve to some extent. The leakage of the magnetic flux lines can be decreased through increasing the thickness of the valve core or reducing the resistance gaps. Observing figure 5(b), it can be found that the distributions of the magnetic flux density in the annular and radial fluid flow gaps are much uniform, while the magnetic flux densities at the radial fluid flow gaps are larger than those at the annular fluid flow gaps. In this case, the MR fluid at the radial fluid flow gaps will be saturated earlier than that at the annular fluid flow gaps when the applied current increases.

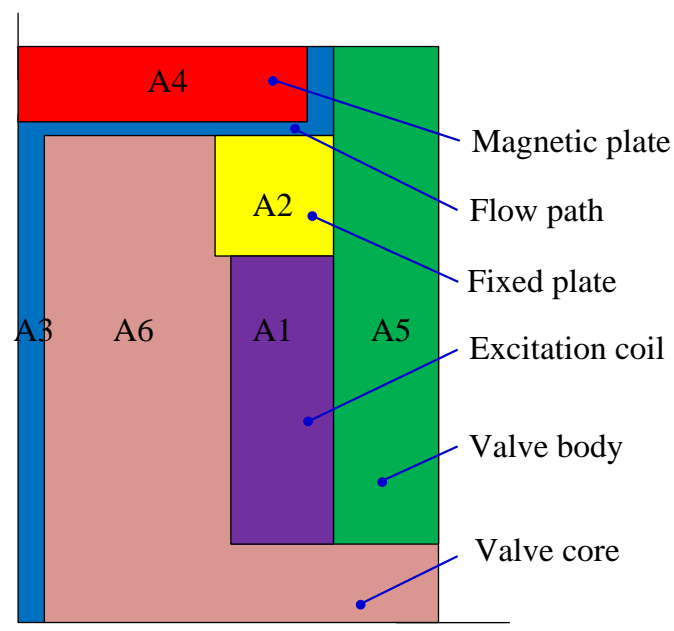

(a)

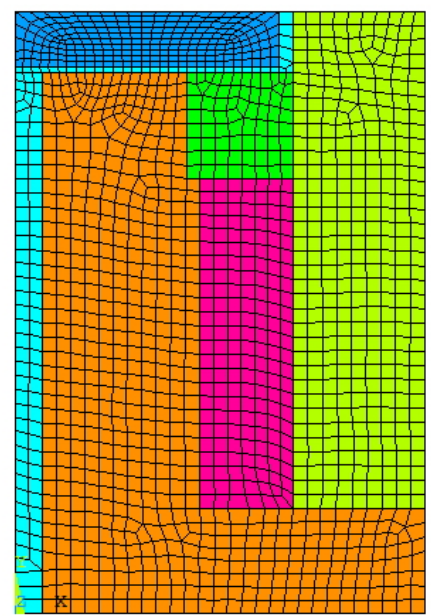

(b)

Figure 4. Two-dimensional finite element model of the MR valve: (a) entity model and (b) meshed model.

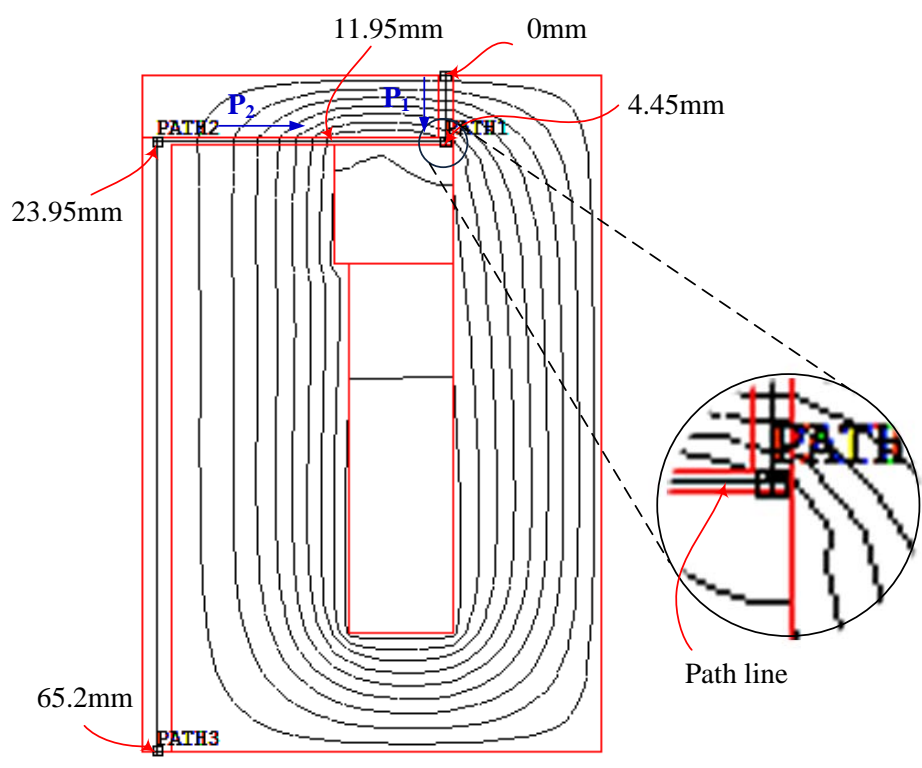

(a)
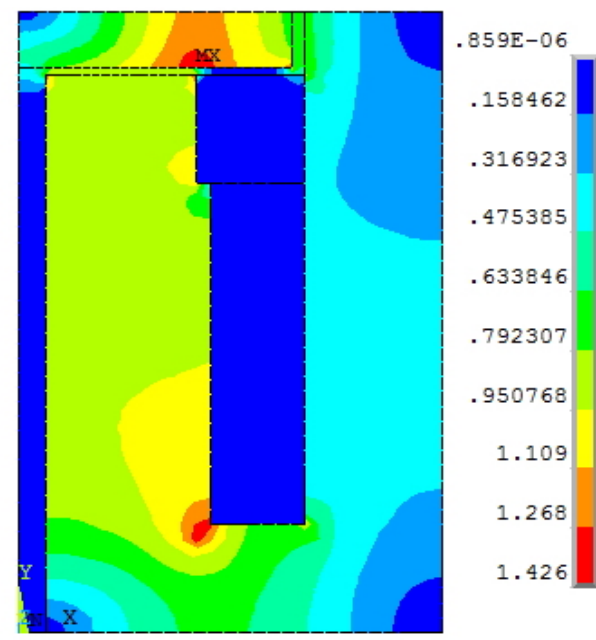

(b)

Figure 5. Finite element analysis of the magnetic circuit of the MR valve: (a) distribution of the magnetic flux line and (b) contour of the magnetic flux density

In order to investigate the distribution of the magnetic flux density in the fluid flow paths clearly, the path $\mathrm{P}_{1}$ along the annular fluid flow path and the path $\mathrm{P}_{2}$ along the radial fluid flow path were 
defined separately, and the dimensions of the total fluid flow paths are also listed, as shown in Figure 5(a). Figure 6 shows the magnetic flux density along the defined path in the annular fluid flow path and in the radial fluid flow path, respectively. It can be seen that the magnetic flux density both in the annular fluid flow path and in the radial fluid flow path distributes evenly though it decreases sharply at the end of the defined path. In addition, the magnetic flux density at the radial fluid flow path is larger than that at the annular fluid flow path. The average magnetic flux density in the annular fluid flow path is $0.795 \mathrm{~T}$, and the average magnetic flux density in the radial fluid flow path is $0.698 \mathrm{~T}$ when the current applied to the excitation coil is $1.0 \mathrm{~A}$.

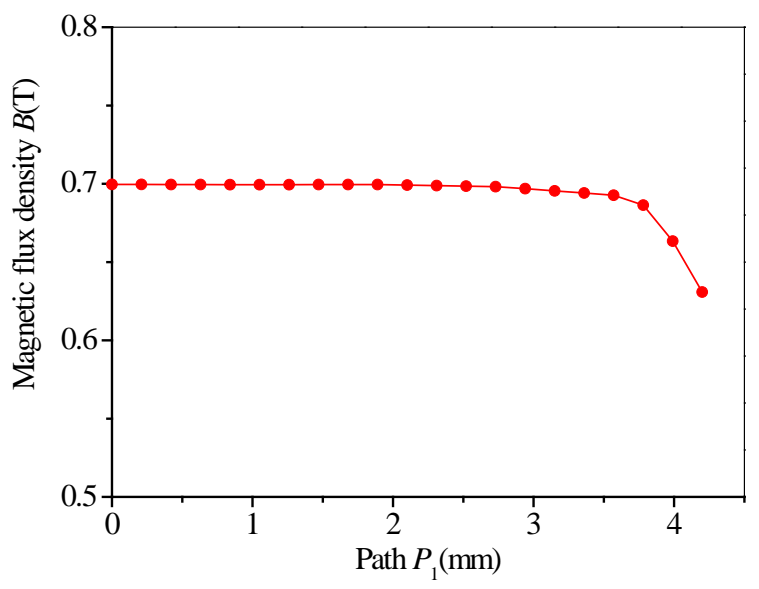

(a)

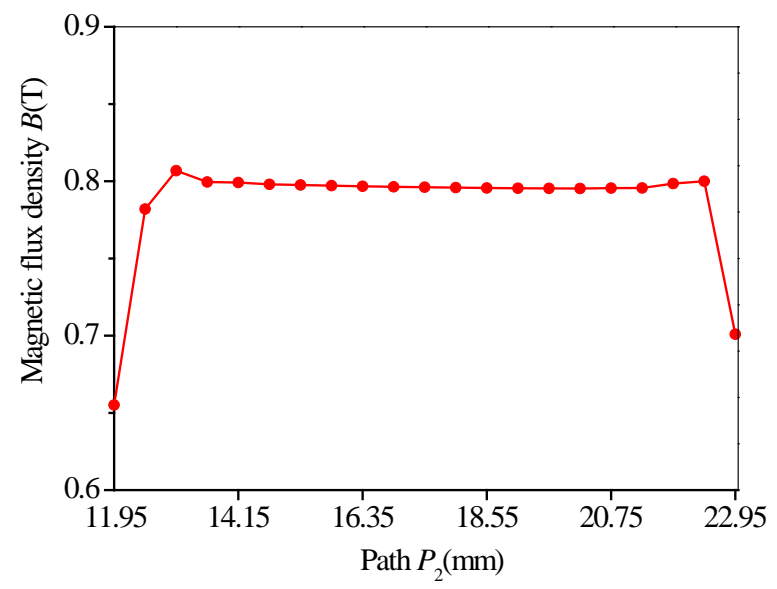

(b)

Figure 6. Magnetic flux density along the defined fluid flow path: (a) in the annular fluid flow gap and (b) in the radial fluid flow gap

Figure 7 shows the distribution of the magnetic flux density along the fluid flow paths that shown in figure 5(a) under different applied current. It can be seen that the magnetic flux density increased with the increment of the applied current both in the annular and radial resistance gap, and the magnetic flux density in the radial fluid flow path is bigger than that in the annular fluid flow path. However, the deviation of the magnetic flux density in the radial and annular resistance gap is not big, which show that the high utilization of the magnetic flux density through structural design for the proposed MR valve.

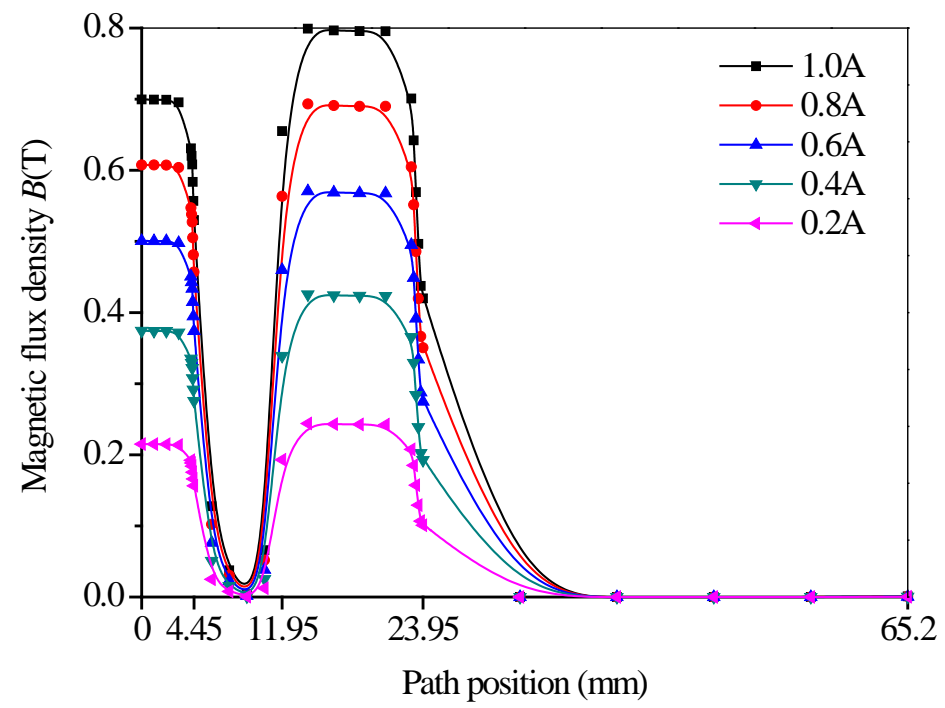

Figure 7. Magnetic flux density along the fluid flow path

Figure 8 shows the dynamic yield stress along the fluid flow path under different applied current. 
The trend of the yield stress variation is shown to be the similar to the trend of the magnetic flux density variation as depicted in figure 7 when the current is applied from 0 A to $0.6 \mathrm{~A}$. However, the values of the yield stress remain unchanged when the applied current exceeds $0.6 \mathrm{~A}$, the reason is that the dynamic yield stress is saturated under this applied current.

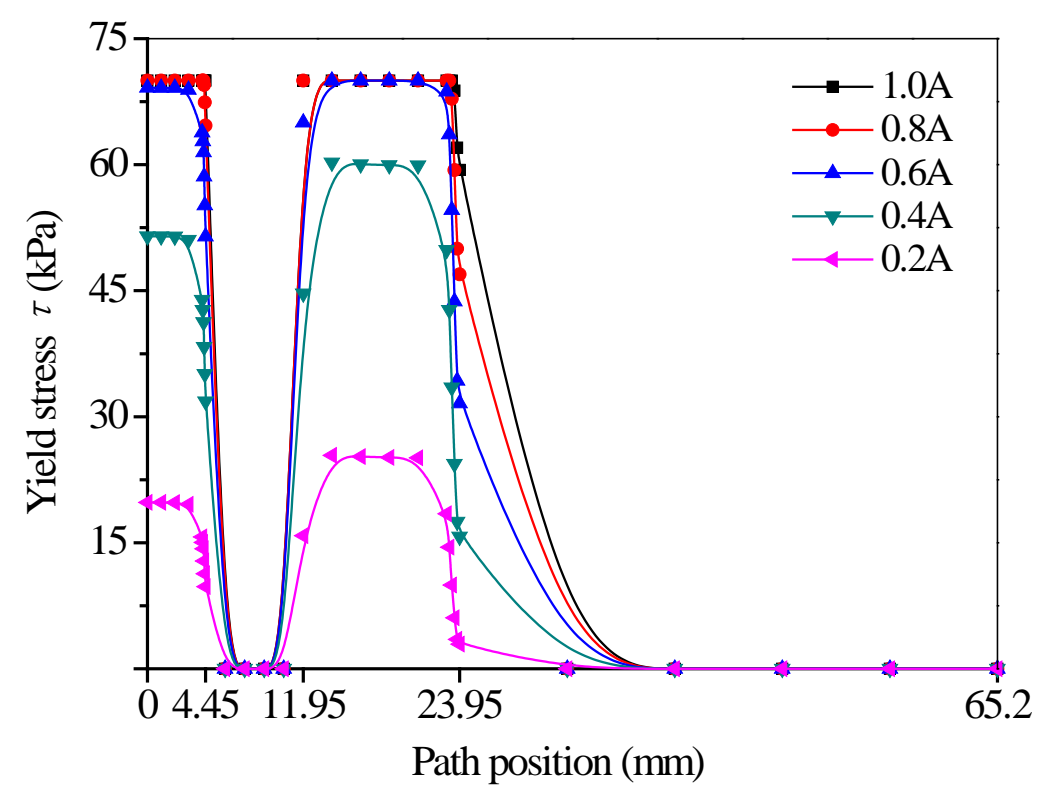

Figure 8. Dynamic yield stress along the fluid flow path

Figure 9 is the yield stress and the estimation of pressure drop under different applied current. As shown in the figure, the yield stress both in the annular and radial resistance gap increased with the increasing of the applied current, and are saturated after the applied current of 0.6 A. At the same time, the total pressure drop also increased with the increment of the applied current, and the maximum pressure drop is about $2450 \mathrm{kPa}$.

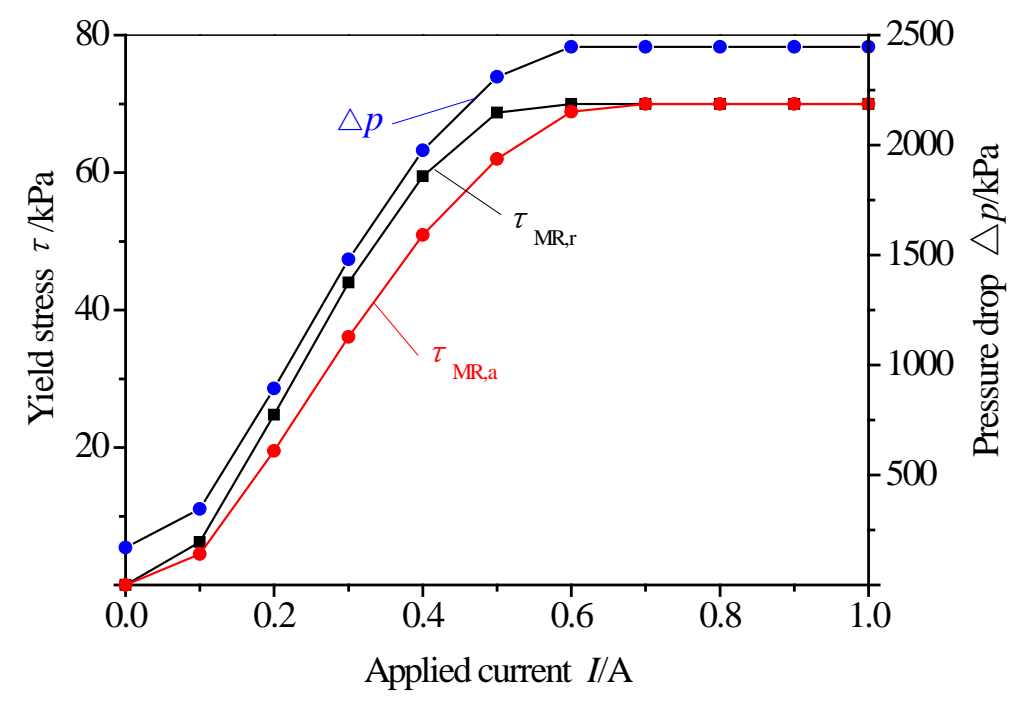

Figure 9. Yield stress and estimated pressure drop under different applied current

\section{Performance analysis of the MR valve with annular-radial-orifice flow paths}

\subsection{Prototyping of the proposed MR valve}

The thickness of the fluid flow resistance gap is an important parameter that affects the performance 
of MR valves. The magnetic resistance in the fluid flow gap is much larger than that of other structures of MR valve. A larger gap thickness changes the magnetic circuit and decreases the magnetic flux density, which decreases the MR effect. The MR fluid is difficult to pass through the resistance gap if the gap thickness is too small. In general, the reasonable gap thickness ranges between $0.5 \mathrm{~mm}$ and $1.5 \mathrm{~mm}$. In this work, the radial resistance gap size is set as $0.5 \mathrm{~mm}$ and the annular resistance gap size is set as $1.0 \mathrm{~mm}$, respectively.

In order to make full use of magnetic flux density both in the radial resistance gap and annular resistance gap, the magnetic flux density in the radial flow channel was designed to be roughly equal to that in the annular flow channels, so the reasonable resistance length of $L_{\mathrm{r}}$ and $L_{\mathrm{a}}$ can also be obtained. From equation (3), it can be deduced that

$$
B_{M R, r} S_{M R, r}=B_{M R, a} S_{M R, a}
$$

As $B_{\mathrm{MR}, \mathrm{r}}$ is roughly equal to $B_{\mathrm{MR}, \mathrm{a}}$, so $S_{\mathrm{MR}, \mathrm{r}}$ is also roughly equal to $S_{\mathrm{MR}, \mathrm{a}}$. According to equation (5) and the simulation results in section 3.2, the relationship of $L_{\mathrm{r}}$ and $L_{\mathrm{a}}$ can be determined. Here, the length of the annular resistance gap $L_{\mathrm{a}}$ is $4.2 \mathrm{~mm}$, and the length of the radial magnetized resistance gap $L_{\mathrm{r}}$ is $11 \mathrm{~mm}$.

Figure 10 shows the prototype of the proposed MR valve with annular-radial-orifice flow paths, and Table 1 summarises the primary parameters of the proposed MR valve.

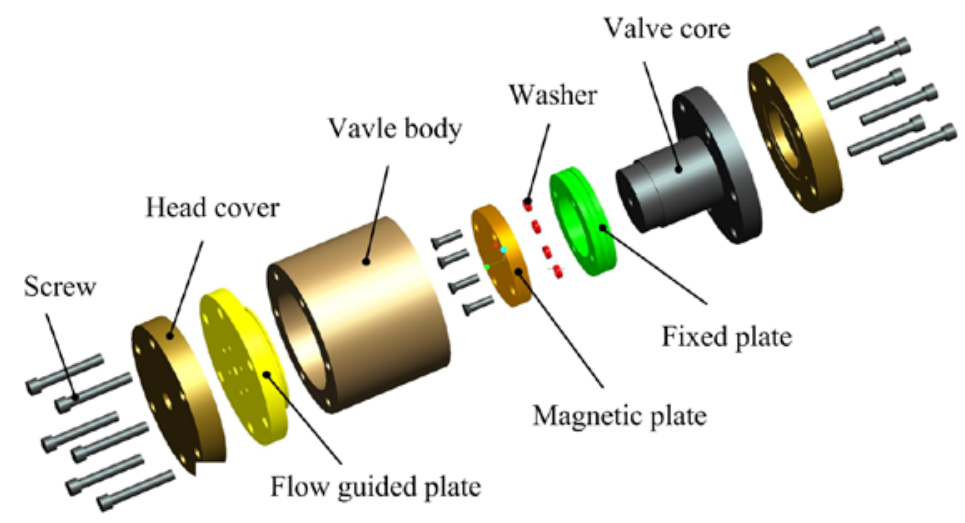

(a)

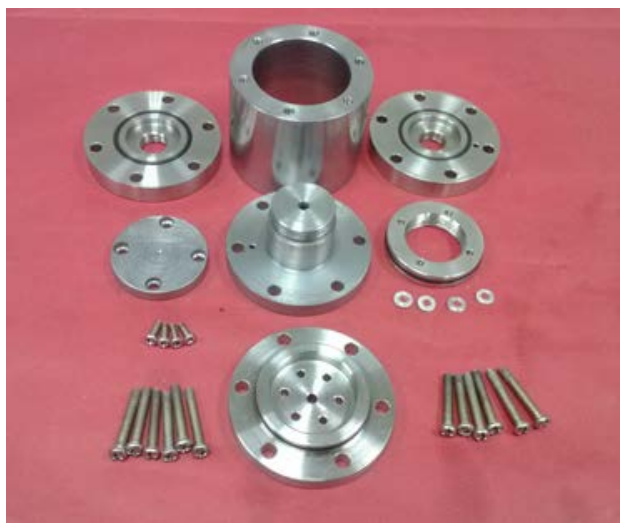

(b)

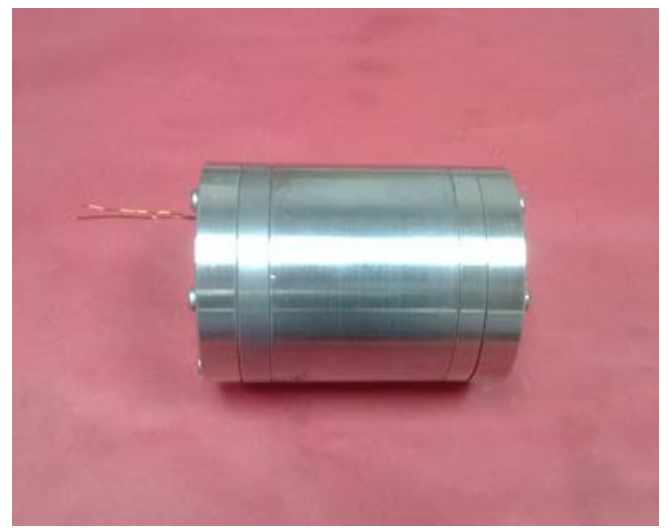

(c)

Figure 10. Photograph of the manufactured MR valve: (a) 3D model, (b) manufactured component, and (c) assembly valve. 
Table 1. Primary parameters of the proposed MR valve

\begin{tabular}{c|l|c|c}
\hline Parameters & \multicolumn{1}{|c|}{ Descriptions } & Units & Values \\
\hline$\eta$ & Fluid viscosity without magnetic field & Pa·s & 0.8 \\
$q$ & System flow rate & $\mathrm{L} / \mathrm{min}$ & 4 \\
$g_{\mathrm{a}}$ & Annular gap size & $\mathrm{mm}$ & 1 \\
$g_{\mathrm{r}}$ & Radial gap size & $\mathrm{mm}$ & 0.5 \\
$t_{\mathrm{h}}$ & Thickness of the valve body & $\mathrm{mm}$ & 10 \\
$R$ & MR valve radius & $\mathrm{mm}$ & 31 \\
$L$ & Length of the valve core & $\mathrm{mm}$ & 41 \\
$W_{c}$ & Groove thickness & $\mathrm{mm}$ & 7 \\
$R_{\mathrm{o}}$ & Orifice radius & $\mathrm{mm}$ & 2 \\
$R_{\mathrm{d}}$ & Radius at the left end of valve core with screw & $\mathrm{mm}$ & 13 \\
$R_{\mathrm{c}}$ & Radius at the left end of valve core without screw & $\mathrm{mm}$ & 14 \\
$t_{\mathrm{c}}$ & Thickness of the right end of valve core & $\mathrm{mm}$ & 8 \\
$L_{\mathrm{a}}$ & Length of the annular resistance gap & $\mathrm{mm}$ & 4.2 \\
$L_{\mathrm{r}}$ & Length of the radial magnetized resistance gap & $\mathrm{mm}$ & 11 \\
$t_{\mathrm{d}}$ & Thickness of the fixed plate & $\mathrm{mm}$ & 8 \\
\hline
\end{tabular}

\subsection{Experimental test rig setup}

In order to validate the valve performance of the proposed MR valve, an experimental test rig was built up and shown in Figure 11. A motor driven fixed gear pump was used as a power unit. Two pressure transducers $a$ and $b$ were used to measure the inlet pressure and the outlet pressure of the MR valve, respectively. A relief valve (a) was used as a safety valve to protect the hydraulic system, and a relief valve (b) was used to simulate the load cases. A DC power (a) was used to supply power to the two pressure transducers, and the DC power (b) was used to supply power for the exciting coil of the proposed MR valve. A data acquisition board was used to capture the pressures. A host computer was used to monitor the relevant test parameters of the hydraulic system in real time.

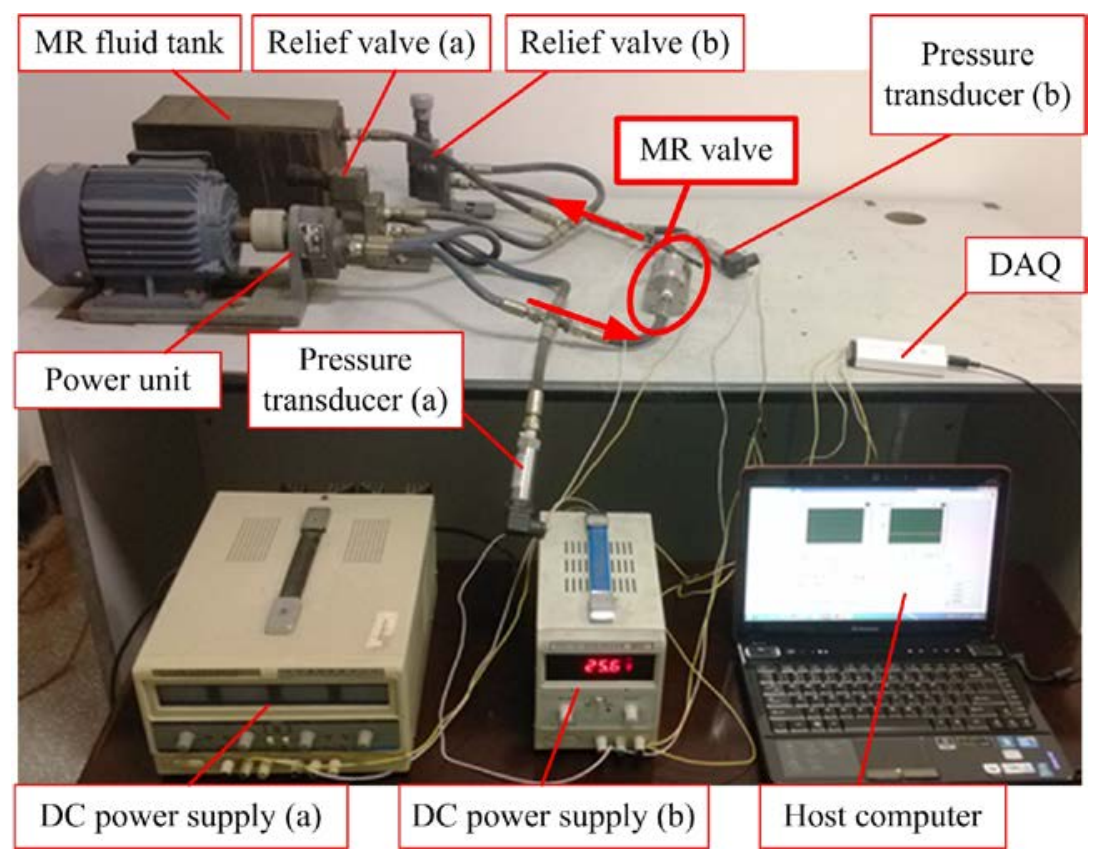

Figure 11. Experimental test rig of the proposed MR valve 


\subsection{Experimental results analysis}

Figure 12 shows the pressure drop of the proposed MR valve without the applied current, and the theoretical value of the pressure drop without the applied current is also presented simultaneously. The experimental pressure drop across the MR valve without the applied current is the pressure difference between the inlet port and the outlet port of the MR valve, which is measured by the pressure transducers a and $b$, respectively. The theoretical pressure drop without the applied current is induced by the viscosity of the MR fluid, which is the sum of the first three terms in equation (16). Observing figure 12, the experimental pressure drop of the MR valve is larger than the theoretical one. The reason is that the pressure drop induced by the non-flow resistance gaps within the MR valve and the vortex and turbulence in the fluid flow gaps are ignored in the theoretical analysis.

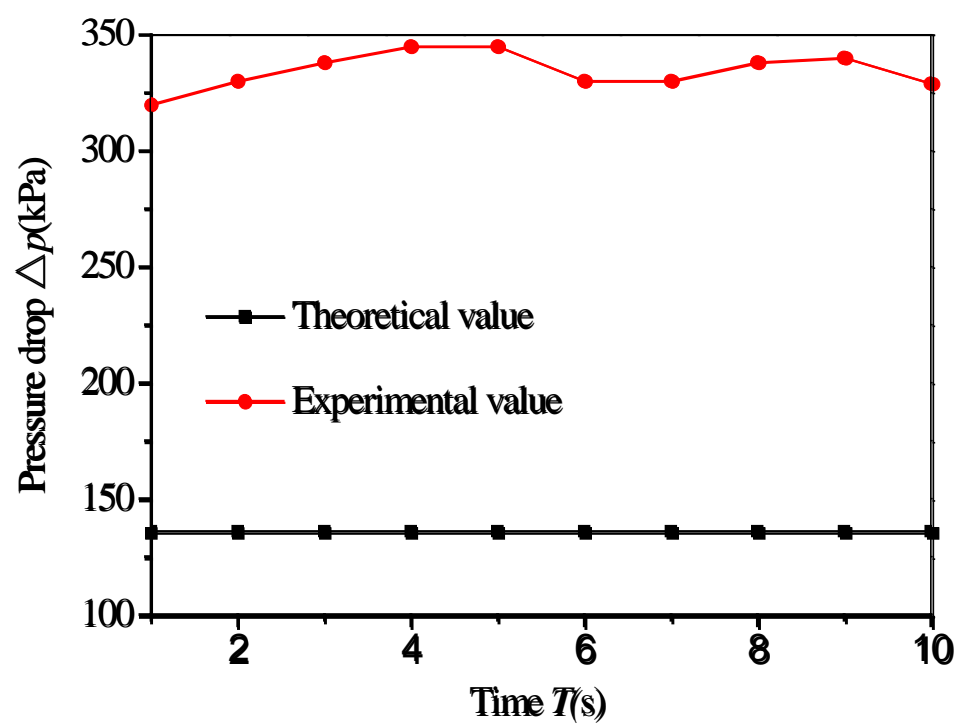

Figure 12. Presure drop of the MR vavle without the applied current.

Figure 13 shows the pressure change of the proposed MR valve under different applied currents. It can be seen that the inlet port pressure and pressure drop increased as the applied currents increased, while the outlet port pressure remained basically unchanged. The reason is that the pressure drop equals a subtraction of the inlet port and outlet port pressures, while the outlet port pressure was held at a certain value by the relief valve (b) that shown in Figure 11. However, the outlet port pressure fluctuated a little because the gears of the fixed gear pump were worn out due to long operating time and the abrasive nature of MR fluid. Observing figure 13 , the maximum experimental pressure drop can reach $2650 \mathrm{kPa}$ when the applied current exceeds $1.2 \mathrm{~A}$. 


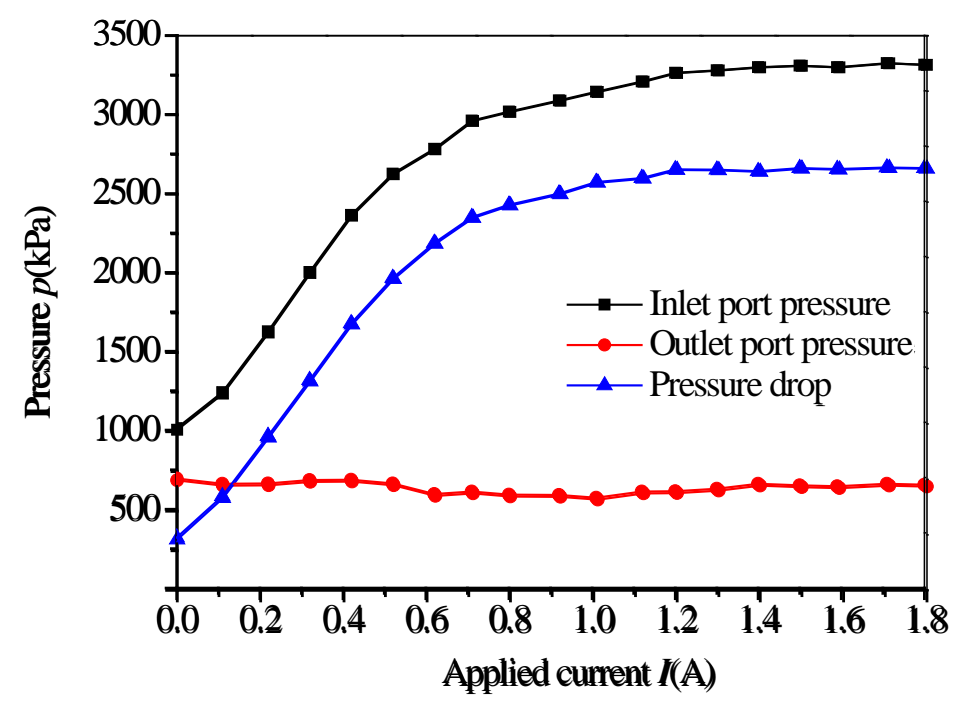

Figure 13. Pressure change under different applied currents

Figure 14 shows the comparison of experimental pressure drop in figure 13 and simulated pressure drop in figure 9. As show in the figure, the simulated pressure drop is saturated earlier than the experimental pressure drop. The reason is that the leakage of the magnetic flux density in the simulation and the air resistance gap in the simulation model were neglected. In addition, the experimental pressure drop is greater than the simulated pressure drop though the difference is little when the applied current exceeds $1.0 \mathrm{~A}$. The reason may be the thickening effect of the used MR fluid, while the Bingham fluid model used in the simulations did not consider this effect [Imaduddin et al. (2014)].

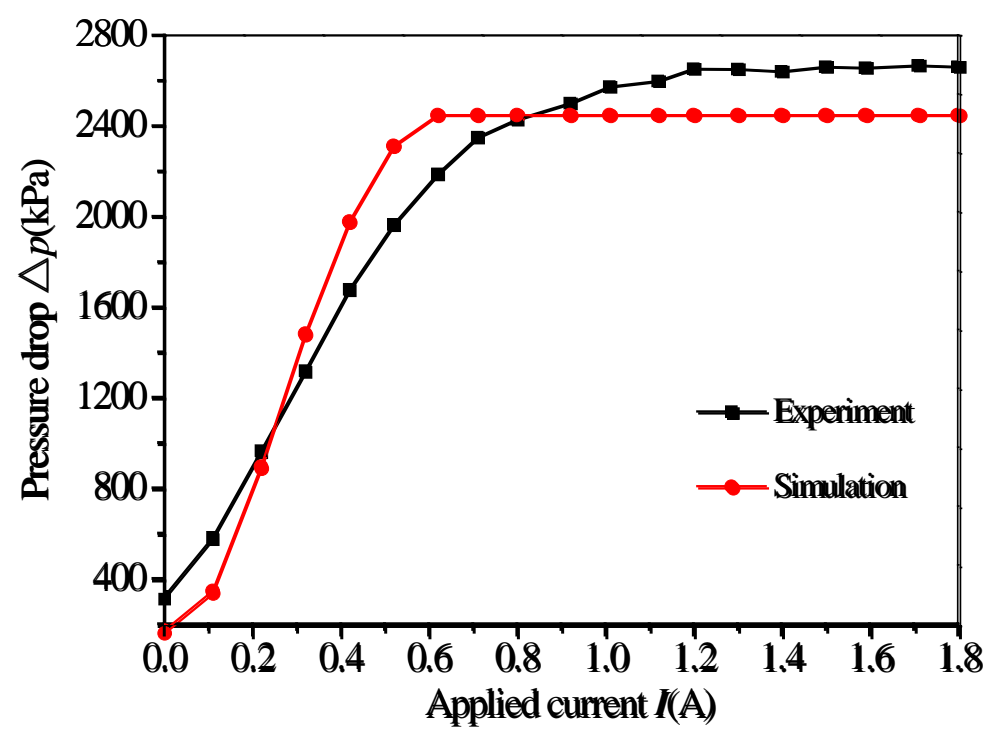

Figure 14. Pressure drop comparison of simulated results and experimental results

The hysteresis of the MR valve was primarily the result of magnetic hysteresis and fluid dynamics. Figure 15 shows the hysteresis of pressure drop under continuously applied currents ranging from $0 \mathrm{~A}$ to $1.8 \mathrm{~A}$, and from $1.8 \mathrm{~A}$ to $0 \mathrm{~A}$. In this case, the percentage of the hysteresis is expressed as the difference between the increasing and decreasing pressure drop divided by the maximum pressure drop. The hysteresis is about $1.5 \%$, which is superior to the servo valve used in the hydraulic oil systems. 


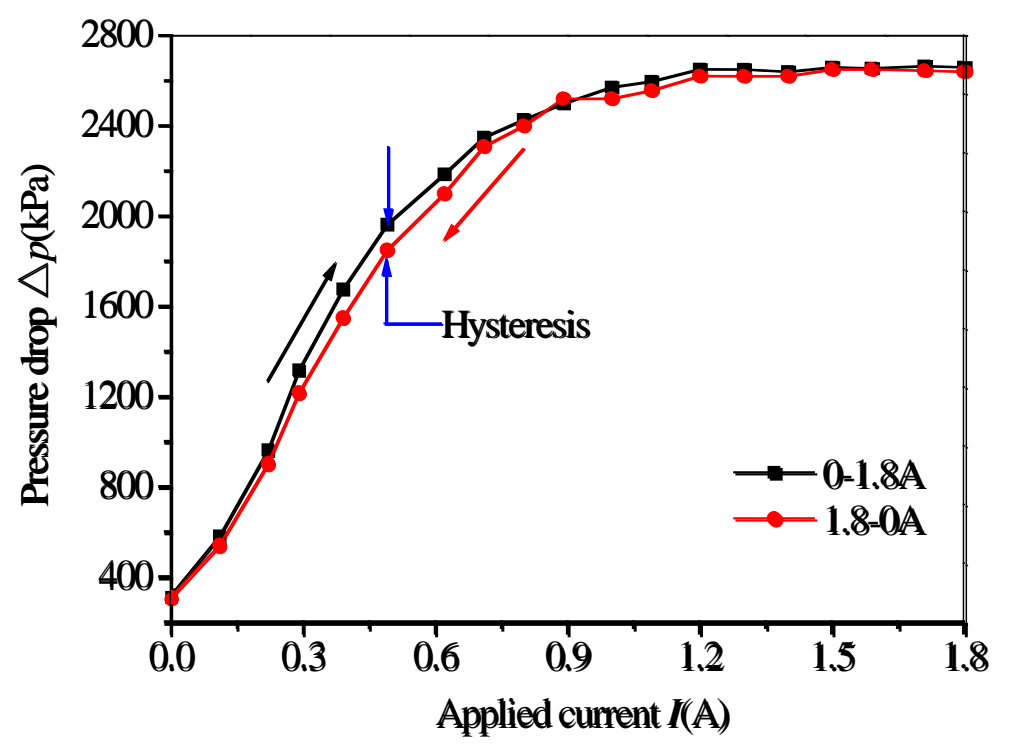

Figure 15. The hysteresis of the pressure drop

The relief valve (b) was applied in the experimental test rig to simulate the loading conditions in the hydraulic system, and three typical load cases were selected by adjusting the outside valve knob of the relief valve (b) in this study. The load case 1 was denoted by adjusting the outside valve knob one clockwise circle at the initial state, the load case 2 was denoted by adjusting the outside valve knob two clockwise circles at the initial state, and the load case 3 was denoted by adjusting the outside valve knob three clockwise circles at the initial state. Figure 16 shows the variation of pressure drop and load cases under different applied currents. Here the pressure drop remained stable at a certain value when the currents were increased from $0 \mathrm{~A}$ to $1.8 \mathrm{~A}$ under the three different load cases, which means the load cases do not influence the pressure drop basically. This characteristic made the MR valve can be used to control the actuators within a high frequency range. Such as, it can be adopted to control the MR damper as a bypass valve, which can effectively increase the dynamic range of the damper. Observing the figure 16, it is also seen that the pressure drop increased as the applied current increased, specifically.

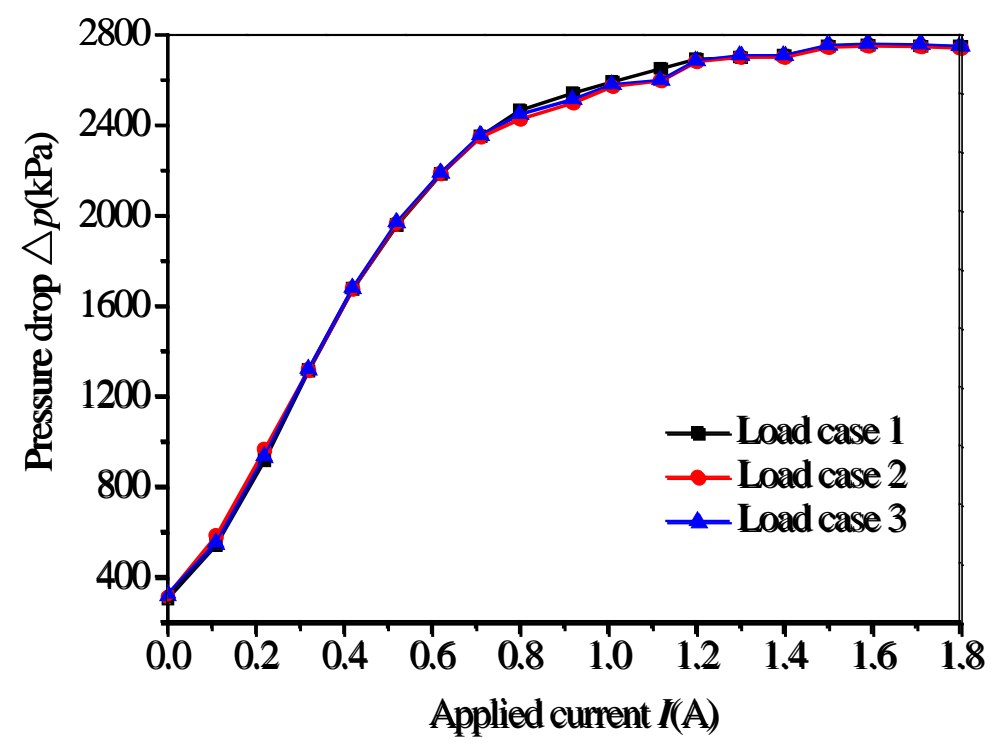

Figure 16. The variation of pressure drop under three typical load cases 


\section{Conclusions}

A compact annular-radial-orifice flow MR valve with $1.0 \mathrm{~mm}$ width of annular resistance gap and $0.5 \mathrm{~mm}$ width of radial resistance gap was developed and prototyped in this paper, the fluid flow paths of the proposed MR valve consisted of a single annular flow channel, a single radial flow channel and an orifice flow channel through structural design. In order to obtain the maximum dynamic yield stress both in the annular and radial resistance gaps together, the optimal analysis was carried out to investigate the relationship of magnetic flux density along the defined paths through magnetic circuit design and finite element analysis. The simulation results show that this design methodology can provide a larger pressure drop of $2450 \mathrm{kPa}$ at the applied current of $0.6 \mathrm{~A}$, which constrained in a volume space of MR valve with an outer diameter of $62 \mathrm{~mm}$ and overall length of $80 \mathrm{~mm}$.

Meanwhile, the valve performance, especially the pressure drop, was investigated from the view of theory calculation, simulation analysis and experiment tests. The experimental pressure drop can reach $2650 \mathrm{kPa}$ at the applied current of $1.2 \mathrm{~A}$, and it was well accorded with the simulation results. This proposed MR valve has significantly improved its efficiency through structural design, which is beneficial to control the MR damper as a bypass control valve for its good pressure regulating capability.

\section{Acknowledgements}

This research was financially supported by the National Natural Science Foundation of China (No. 51165005, 51475165, 11462004), the Natural Science Foundation of Jiangxi Province of China (No. 20151BAB206035) and the Australian Research Council Discovery Project (No. 1501002636).

\section{References}

Abd Fatah AY, Mazlan SA, Koga T, et al. (2015) A review of design and modeling of magnetorheological valve. International Journal of Modern Physics B 29(04): 1530004.

Ai HX, Wang DH and Liao WH (2006) Design and modeling of a magnetorheological valve with both annular and radial flow paths. Journal of Intelligent Material Systems and Structures 17(4): 328-334.

Aydar G, Wang X and Gordaninejad F (2010) A novel two-way-controllable magneto-rheological fluid damper. Smart Materials and Structures 19(6): 065024.

De Vicente J, Klingenberg DJ and Hidalgo-Alvarez R (2011) Magnetorheological fluids: a review. Soft Matter 7(8): 3701-3710.

Gordaninejad F, Wang X, Hitchcock G, et al. (2010) Modular high-force seismic magneto-rheological fluid damper. Journal of Structural Engineering 136(2): 135-143.

Hadadian A, Sedaghati R and Esmailzadeh E (2014) Design optimization of magnetorheological fluid valves using response surface method. Journal of Intelligent Material Systems and Structures 25(11): 1352-1371.

Hu GL, Long M, Huang M, et al. (2014a) Design, analysis, prototyping, and experimental evaluation of an efficient double coil magnetorheological valve. Advances in Mechanical Engineering 6: 403410.

$\mathrm{Hu}$ GL, Long M, Yu LF, et al. (2014b) Design and performance evaluation of a novel 
magnetorheological valve with a tunable resistance gap. Smart Materials and Structures 23(12): 127001.

Imaduddin F, Mazlan SA, Rahman MAA, et al. (2014) Ubaidillah and Ichwan B. A high performance magnetorheological valve with a meandering flow path. Smart Materials and Structures 23(6): 065017.

Imaduddin F, Mazlan S A, Zamzuri H, et al. (2015) Design and performance analysis of a compact magnetorheological valve with multiple annular and radial gaps. Journal of Intelligent Material Systems and Structures 26(9): 1038-1049.

Jolly MR, Bender JW and Carlson JD (1999) Properties and applications of commercial magnetorheological fluids. Journal of Intelligent Material Systems and Structures 10(1): 5-13.

Kostamo E, Kostamo J, Kajaste J, et al. (2012) Magnetorheological valve in servo applications. Journal of Intelligent Material Systems and Structures 23(9): 1001-1010.

Liao CR, Zhao DX, Xie L, et al. (2012) A design methodology for a magnetorheological fluid damper based on a multi-stage radial flow mode. Smart Materials and Structures 21(8): 085005.

Liu B, Li WH, Kosasih PB, et al. (2006) Development of an MR-brake-based haptic device. Smart Materials and Structures 15(6): 1960-1966.

Li WH, Du H (2003) Design and experimental evaluation of a magnetorheological brake. International Journal of Advanced Manufacturing Technology 21(7): 508-515.

Li WH, Du H and Guo NQ (2003) Finite element analysis and simulation evaluation of a magnetorheological valve. The International Journal of Advanced Manufacturing Technology 21(6): 438-445.

McLaughlin G, Hu W and Wereley NM (2014) Advanced magnetorheological damper with a spiral channel bypass valve. Journal of Applied Physics 115(17): 17B532.

Nguyen QH, Choi SB, Lee YS, et al. (2009) An analytical method for optimal design of MR valve structures. Smart Materials and Structures 18(9): 1088-1100.

Nguyen QH, Choi SB, Lee YS, et al. (2013) Optimal design of high damping force engine mount featuring MR valve structure with both annular and radial flow paths. Smart Materials and Structures 22(11): 115024.

Nguyen QH, Choi SB and Wereley NM (2008) Optimal design of magnetorheological valves via a finite element method considering control energy and a time constant. Smart Materials and Structures 17(2): 1-12.

Nguyen QH, Han YM, Choi SB, et al. (2007) Geometry optimization of MR valves constrained in a specific volume using the finite element method. Smart Materials and Structures 16(6): 2242-2252.

Phu DX, Choi SB, Lee YS, et al (2014a) Design of a new engine mount for vertical and horizontal vibration control using magnetorheological fluid. Smart Materials and Structures 23(11): 117001.

Phu DX, Shah K and Choi SB (2014b) A new magnetorheological mount featured by changeable damping gaps using a moved-plate valve structure. Smart Materials and Structures 23(12): 125022.

Do XP and Choi SB (2015) High Loaded Mounts for Vibration Control Using Magnetorheological Fluids: Review of Design Configuration. Shock and Vibration 915859.

Rosenfeld NC and Wereley NM (2004) Volume-constrained optimization of magnetorheological and electrorheological valves and dampers. Smart Materials and Structures 13(6): 1303-1313.

Salloom MY and Samad Z (2011a) Design and modeling magnetorheological directional control valve. Journal of Intelligent Material Systems and Structures 23(2): 155-167. 
Salloom MY and Samad Z (2011b) Finite element modeling and simulation of proposed design magneto-rheological valve. The International Journal of Advanced Manufacturing Technology 54(5-8): 421-429.

Salloom MY and Samad Z (2012) Magneto-rheological directional control valve. The International Journal of Advanced Manufacturing Technology 58(1-4): 279-292.

Yoo JH and Wereley NM (2002) Design of a high-efficiency magnetorheological valve. Journal of Intelligent Material Systems and Structures 13(10): 679-685.

Yoo JH and Wereley NM (2004) Performance of a magnetorheological hydraulic power actuation system. Journal of Intelligent Material Systems and Structures 15(11): 847-858.

Yoshida K, Soga T, Kawachi M, et al. (2010) Magneto-rheological valve-integrated cylinder and its application. Proceedings of the Institution of Mechanical Engineers, Part I: Journal of Systems and Control Engineering 224(1): 31-40.

Zhu XC, Jing XJ and Cheng L (2013) Optimal design of control valves in magnetorheological fluid dampers using a nondimensional analytical method. Journal of intelligent material systems and structures 24(1): 108-129. 